\title{
As origens históricas da diplomacia e a evolução do conceito de proteção diplomática dos nacionais
}

\author{
The Historical Origins of Diplomacy \\ and the Evolution of the Concept of Diplomatic \\ Protection of Citizens Abroad
}

\author{
Elen de Paula Bueno* \\ Marina Freire** \\ Victor Arruda Pereira de Oliveira***
}

\begin{abstract}
SUMÁRIO: I. Introdução. II. O surgimento e desenvolvimento da diplomacia tradicional: a prevalência dos interesses do Estado. III. Emer deVattel e a proteção diplomática dos nacionais. IV. A proteção dos interesses do Estado e de seus nacionais: o indivíduo como objeto ou sujeito de direito internacional?. V. Conclusão. VI. Bibliografia.
\end{abstract}

\footnotetext{
* Advogada e Doutoranda em Direito Internacional pela Universidade de São Paulo (USP). Mestre em Integração da América Latina pelo Programa de Pós-Graduação em Integração da América Latina pela Universidade de São Paulo - PROLAM/USP. É Bacharel em Direito e em Relações Internacionais pela Universidade Estadual Paulista - UNESP.

** Juíza de Direito. Mestranda em Direito Internacional pela Universidade de São Paulo (USP).

*** Advogado e Mestrando em Direito Internacional pela Universidade de São Paulo (USP). Bacharel em Direito pela Faculdade de Direito da Universidade de São Paulo (USP).
}

Artículo recibido el 10 de febrero de 2016 Aprobado para publicación el 22 de septiembre de 2016 
RESUMO: o presente artigo pretende discorrer acerca da proteção diplomática de nacionais, levando-se em conta a evolução histórica da diplomacia e do direito diplomático, as contribuições doutrinárias, sobretudo de Emer de Vattel, bem como as recentes decisões internacionais em matéria de proteção diplomática de nacionais. Por fim, mostraremos as principais mudanças relativas ao tema, mormente no tocante à necessidade de ajustar o conceito tradicional da proteção diplomática à realidade do mundo pós-moderno.

Palavras-chave: direito diplomático, proteção diplomática, Emer de Vattel, Sujeitos de Direito Internacional.

ABSTRACT: this article aims to discuss the diplomatic protection of citizen abroad, taking into account the historical development of diplomacy and the diplomatic law, the doctrinal contributions, especially Emer de Vattel, as well as the current international decisions on protection of citizen abroad. Finally, we will show the major changes relating to the issue, especially regarding the need to adjust the traditional concept of diplomatic protection to the reality of the postmodern world.

Key words: Diplomatic Law, Diplomatic Protection, Emer de Vattel, Subjects of International Law.

RÉSUMÉ: Cet article a pour but de discuter la protection diplomatique des nationaux à l'étranger, en tenant compte de l'évolution historique de la diplomatie et du droit diplomatique, les contributions doctrinales, en particulier de Emer de Vattel, ainsi que les décisions internationales récentes sur la protection diplomatique de nationaux. Enfin, nous allons montrer les principaux changements liés à ce sujet, en particulier en ce qui concerne la nécessité d'adapter le concept traditionnel de la protection diplomatique à la réalité du monde postmoderne.

Mots-clés: Droit Diplomatique, Protection Diplomatique, Emer de VATTEL, Sujets du Droit International. 
Esta revista forma parte del acervo de la Biblioteca Jurídica Virtual del Instituto de Investigaciones Jurídicas de la UNAM

\section{INTRODUÇÃO}

O desenvolvimento da diplomacia ${ }^{1}$ confunde-se com a atividade internacional dos Estados que, durante séculos, representou sobretudo a consecução dos interesses nacionais, delineada no âmbito da política externa e executada alhures mediante representações consulares e diplomáticas.

A diplomacia, desde a mais remota antiguidade, constituiu importante instrumento de promoção dos interesses dos Estados e se consolidou como relevante mecanismo de solução pacífica de controvérsias nas relações internacionais. Outrossim, desempenhou importante papel no desenvolvimento das atividades comerciais, originariamente principal objeto da proteção diplomática.

A proteção dos nacionais entre as funções da missão diplomática encontrou na doutrina clássica as primeiras delimitações concernentes ao tema. Na obra de Emer de Vattel, O Direito das Gentes, de 1758, podemos encontrar uma das primeiras referências em matéria de proteção diplomática de nacionais, entendida essencialmente como direito do Estado. Tal perspectiva, desenvolvida no âmbito da doutrina moderna e que perdurou por séculos, tratou de colocar o indivíduo como objeto da proteção diplomática e não como sujeito desta.

Ao longo do século XX, a doutrina e a jurisprudência passaram a ajustar o conceito tradicional da proteção diplomática à realidade do mundo pós-moderno, porquanto a maior parte dos investimentos estrangeiros estaria ligada à atividade desenvolvida por pessoas jurídicas. Igualmente, a mudança de paradigma passou a questionar o papel do indivíduo como objeto da proteção diplomática e essencialmente submetido à completa tutela dos Estados. De tal contexto, surgiram as teorias que hodiernamente defendem os indivíduos como destinatários do direito internacional, adaptação que julgam premente no contexto pós-moderno.

O presente artigo pretende, à luz das observações supramencionadas, traçar o desenvolvimento da proteção diplomática dos nacionais até as mais

1 Para Accioly, trata-se da "arte de representar os Estados, uns perante os outros, ou o conjunto de regras práticas referentes às relações pacíficas e as negociações entre os estados”. Accioly, Hildebrando, Tratado de direito internacional público, São Paulo, Quartier Latin, 2009, p. 533. 
recentes discussões desenvolvidas no âmbito da doutrina e da jurisprudência. Para tanto, na primeira parte do artigo, traçaremos um breve histórico do desenvolvimento da diplomacia até sua bem-sucedida codificação consubstanciada na Convenção de Viena sobre Relações Diplomáticas de 1961 e na Convenção de Viena sobre Relações Consulares de 1963. À luz de tal delineação, tentaremos demonstrar como o desenvolvimento da diplomacia esteve historicamente ligado à promoção e à proteção dos interesses estatais. Posteriormente, passaremos à análise da contribuição de Emer de Vattel em matéria de proteção diplomática de nacionais, precipuamente as delimitações desenvolvidas pelo filósofo. Finalmente, abordaremos as recentes contribuições doutrinárias e as principais decisões de tribunais internacionais de modo a aferir quais as principais mudanças ao longo das últimas décadas no tocante à proteção diplomática de nacionais.

\section{O SURGIMENTO E DESENVOLVIMENTO DA DIPLOMACIA TRADICIONAL:} A PREVALÊNCIA DOS INTERESSES DO ESTADO

A diplomacia tradicional foi paulatinamente estruturada e desenvolvida, durante séculos, desde a mais remota antiguidade. O surgimento da diplomacia se confunde com o tempo histórico, no sentido de ser concomitante aos primeiros registros remanescentes de história escrita, que se manifesta por meio de tratados ${ }^{2}$ e em diversas regiões do mundo.

Foi na Mesopotâmia onde se concluiu o tratado mais antigo do qual se tem registro. Trata-se do tratado entre Eannatum, soberano da cidade de Lagash e a cidade de Umma, escrito em língua suméria e o qual fixava limites de fronteiras. ${ }^{3}$

$\mathrm{Na}$ China, as práticas diplomáticas já alcançavam conteúdos complexos e detalhados na Antiguidade, ${ }^{4}$ funcionando como uma das formas mais eficazes de diálogo e contenção de conflitos entre os povos vizinhos. ${ }^{5} \mathrm{~A}$ influên-

2 Nascimento e Silva, G. E. et al., O. Direito Internacional Diplomático. Convenção deViena sobre Relações Diplomáticas na Teoria e na Prática, São Paulo, Saraiva, 2012, p. 22.

3 Truyol y Serra, História del Derecho Internacional Público, Madrid, Tecnos, 1998, p. 19.

4 Morton, W. Scott. China: história e cultura. Rio de Janeiro: Zahar Editores, 1986, p. 112.

5 Spence, Jonathan D. Em busca da China moderna: quatro séculos de história, trad. de Tomás R. Bueno e Pedro M. Soares, São Paulo, Companhia das Letras, 1996, pp. 147-213. 
Esta revista forma parte del acervo de la Biblioteca Jurídica Virtual del Instituto de Investigaciones Jurídicas de la UNAM

cia confuciana também esteve presente entre os povos vizinhos do império do meio, os quais desenvolveram importantes institutos diplomáticos e aperfeiçoaram a criação de carreiras públicas mediante concursos periódicos para o recrutamento de homens de talento, inclusive para a arte diplomática, assim como exigia a Dinastia Lý, no atual Vietnã. ${ }^{6}$ Outros povos igualmente forneceram aportes para o desenvolvimento histórico da diplomacia e todos os institutos que a norteiam, como os povos islâmicos, os quais tiveram um importante papel na contribuição da construção do direito das gentes e especificamente do direito diplomático, mormente no que diz respeito ao reconhecimento da inviolabilidade dos embaixadores e ao respeito do cumprimento das obrigações convencionais. ${ }^{7}$

Entre os antigos gregos se encontram instituições até hoje conhecidas do direito das gentes, tais como os tratados, a utilização de arbitragem e a inviolabilidade dos arautos. A proxenia é muitas vezes citada dentre as instituições consulares da antiguidade grega dada a importância do acordo de hospitalidade mútua entre os entes políticos e as imunidades conferidas aos seus representantes públicos. ${ }^{8}$

Desde o início da história romana, a falta cometida contra embaixadores era considerada violação do "direito dos povos". Em uma das passagens da História de Roma, Tito Lívio nos mostra a existência e a relevância dos trabalhos dos embaixadores e da consequente existência operativa do que se poderia chamar de diplomacia. ${ }^{9}$

A partir do século XV, a necessidade de institucionalização e de uma convivência pacífica entre os estados italianos levaram ao interessante desenvolvimento da diplomacia. O surgimento da figura do embaixador propiciou uma relevante instauração institucional e o fortalecimento do instituto obteve um papel crucial no período de relativa estabilidade na península italiana. ${ }^{10}$ Nesse sentido, o modelo da diplomacia na Idade Moderna foi dado pelas relações entre os Estados e os príncipes do renascimento na

6 Exposição histórica do Museu Histórico doVietnã: cidade de Ho Chi Minh, 2014.

7 Assim como ressaltou o juiz sírio Tarazi na decisão da Corte Internacional de Justiça sobre o pessoal diplomático e consular dos Estados Unidos em Teerã, disponível em: http: / / www. icj-cij.org/docket $/$ index.php?p1 $=3 \& p 2=3 \&$ code $=u$ sir\&case $=64 \& k=c 9 \& p 3=0 \& l a n g=f r$ (acesso em 26 de agosto de 2014).

8 Casella, Paulo Borba, Direito internacional no tempo antigo, São Paulo, Atlas, 2012, p. 270.

9 Nascimento e Silva, G. E. et al., op. cit., p. 23.

10 Ibidem, p. 27. 
Esta revista forma parte del acervo de la Biblioteca Jurídica Virtual del Instituto de Investigaciones Jurídicas de la UNAM www.juridicas.unam.mx

Itália. A tensão permanente entre principados italianos, mediada pela celebração de tratados e alianças, justificou o recurso a enviados permanentes, residentes e com posto fixo. Florença teve como enviados Dante, Patrarca, Boccacio e, mais tarde, Guicciardini e Maquiavel. A diplomacia de Veneza constituiu um modelo por funcionar regularmente desde o século XIII. ${ }^{11}$

O fortalecimento do direito, da diplomacia e das instituições dentro da península italiana influenciou pequenos Estados - que dispunham de pouca força militar - a utilizarem a diplomacia como principal arma de barganha nas relações internacionais. O domínio de Veneza sobre a República de Ragusa, atual Dubrovnik, contribuiu para o desenvolvimento do direito e instituições, bem como da diplomacia. No século XIII, a então República de Ragusa já possuía Cortes especializadas, uma cível e outra criminal. Posteriormente, adquiriu certa independência em relação aos impérios que a cercavam, como o Otomano, em virtude da desenvolvida diplomacia. ${ }^{12}$

A influência da prática existente entre os Estados italianos, mormente no que diz respeito ao modelo de diplomacia institucionalizada, com embaixadores residentes, propagou-se por toda a Europa e tornou-se parâmetro de organização das relações diplomáticas por séculos. Em matéria de direito diplomático, o costume acabou por nortear, ao longo da história, a evolução das instituições diplomáticas. Foi no Congresso de Viena, de 1815, a primeira tentativa codificadora no sentido de regulamentar a complexidade das classes e dos agentes diplomáticos. O documento jurídico do Congresso de Viena de 1815, realizado após o Tratado de Paris, traduziu os interesses das potências europeias, divididas entre conservadoras (Prússia, Áustria e Rússia) e liberais (Inglaterra e posteriormente também a França) em conter o expansionismo de Napoleão Bonaparte. ${ }^{13}$

11 Homem, António Pedro Barbas, História das Relações Internacionais. O direito as concepções políticas na Idade Moderna, Coimbra, Almedina, 2003, p. 74.

12 Pomorski Musez, Maritime Museum e Rector's Palace, Dubrovnik, 2014.

13 "Déclaration des Puissances signataires du Traité de Paris réunies au Congrès de Vienne au sujet de l'évasion de Napoléon de l'île d'Elbe. Vienne le 13 mars 1815: Les Puissances qui ont signé le Traité de Paris réunies en congrès à Vienne informées de l'évasion de Napoléon Buonaparte et de son entrée à main armée en France doivent à leur propre dignité et à l'intérêt de l'ordre social une déclaration des sentiments que cet événement leur a fait éprouver. En rompant ainsi la Convention qui l'avait établi à l'île d Elbe Buonaparte détruit le seul titre légal auquel son existence se trouvait attachée. En reparaissant en France avec des projets de troubles et de bouleversements il s'est privé lui même de la protection des lois et a manifesté à la face de l'univers qu'il ne saurait y avoir ni paix ni trêve avec lui. Et quoique intimement persuadés que la France entière se ralliant autour de son souverain légitime fera 
Esta revista forma parte del acervo de la Biblioteca Jurídica Virtual del Instituto de Investigaciones Jurídicas de la UNAM

Sob uma perspectiva jurídica, o Congresso de Viena pode ser compreendido à luz de quatro definições relevantes: preparou juridicamente as Constituições da Confederação Germânica e Suíça $;{ }^{14}$ disciplinou a classe hierárquica de agentes diplomáticos; pontuou os primeiros passos rumo à abolição da escravidão de negros e consolidou o princípio de liberdade de navegação em rios internacionais. ${ }^{15}$

A regulamentação constante no Anexo n 17 da Ata Final do Congresso de Viena em 9 de junho de 1815 disciplinou a classe hierárquica dos agentes diplomáticos a fim de tornar mais transparentes e céleres as negociações diplomáticas. ${ }^{16}$ Nos termos do referido Anexo, a classificação dos agentes diplomáticos foi elaborada da seguinte forma: ${ }^{17}$

incessamment rentrer dans le néant cette dernière tentative d'un délire criminel et impuissant tous les souverains de l'Europe animés des mêmes sentiments et guidés par les mêmes principes déclarent que si contre tout calcul il pouvait résulter”. Bibliothèque Diplomatique Comte d'Angeberg. Le Congrés deVienne et les traités de 1815, Paris, Amyot éditeur des archives diplomatiques, 1937, pp. 939 e 940.

${ }_{14}$ Flassan, Gaetan de Raxis, Histoire du Congrés de Vienne, Paris, Chez Treuttel et Wurtz Libraire, 1829, p. 181.

15 Despagnet, Frantz, Cours de Droit International Public, Paris, Elibron Classics, 2006, p. 37.

16 Règlement sur le rang entre les agents diplomatiques. Annexe $n^{\circ} 17$ de l'Acte final du Congrès de Vienne du 9 juin 1815.Pour prévenir les embarras qui se sont souvent présentés et qui pourraient naître encore des prétentions de préséance entre les différents agents diplomatiques, les plénipotentiaires des Puissances signataires du Traité de Paris sont convenus des articles qui suivent, et ils croient devoir inviter ceux des autres têtes couronnées à adopter le même règlement. Art. I. Les employés diplomatiques sont partagés en trois classes: Celle des ambassadeurs, légats ou nonces; Celle des envoyés, ministres ou autres accrédités auprès des souverains; Celle des chargés d'affaires, accrédités auprès des ministres charges des affaires étrangères.

Art. II Les ambassadeurs, légats ou nonces ont seuls le caractere représentatif.

Art. III. Les employés diplomatiques en mission extraordinaire n'ont, à ce titre, aucune supériorité de rang.

Art. IV. Les employés diplomatiques prendront rang entre eux dans chaque classe, d'après la date de la notification officielle de leur arrivée. Le présent règlement n’apportera aucune innovation relativement aux représentants du pape.

Art. V. Il sera déterminé dans chaque Etat un mode uniforme pour la réception des employés diplomatiques de chaque classe.

Art.VI. Les liens de parenté ou d'alliance de famille entre les Cours ne donnent aucun rang à leurs employés diplomatiques. Il en est de même des alliances politiques.

Art. VII. Dans les actes ou traités entre plusieurs Puissances qui admettent l'alternat, le sort décidera entre les ministres de l'ordre qui devra être suivi dans les signatures.

17 Bibliothèque Diplomatique Comte d'Angeberg, Le Congrés deVienn et les traités de 1815. Paris: Amyot éditeur des archives diplomatiques, 1937, pp. 939-940. 
Esta revista forma parte del acervo de la Biblioteca Jurídica Virtual del Instituto de Investigaciones Jurídicas de la UNAM

“Art. I: os agentes diplomáticos estão divididos em três classes:

Embaixadores, legados e núncios;

Enviados, ministros e outros agentes acreditados junto dos soberanos;

Encarregado de negócios, apenas acreditado junto dos ministros dos negócios estrangeiros".

Os esforços na busca de uma sistematização das práticas e das normas prosseguiram no século XIX, notadamente com o advento do Regulamento de imunidades diplomáticas adotado pelo Instituto de Direito Internacional, na sessão de Cambridge, em 1895. Como expõem Nascimento e Silva, Casella e Bittencourt (2012, pp. 37-45), naquela altura já eram situados conceitos cruciais para a regulação da atividade diplomática, como a inviolabilidade diplomática. Posteriormente, como apontam os autores, o Regulamento foi complementado pelas regras adotadas na sessão do Instituto de New York, em 1929, o qual enfatizou o caráter funcional das imunidades atribuídas aos agentes diplomáticos. No mesmo período, vale mencionar a Sexta Conferência Internacional Americana, realizada em Havana, em 1928, que desempenhou importante papel na regulação da instituição diplomática. ${ }^{18}$

As práticas desenvolvidas por diferentes povos e durante um longo período histórico contribuíram para um alto grau de consolidação do direito diplomático, culminando num dos mais bem-sucedidos exemplos de codificação do direito internacional no século XX consubstanciado na Convenção de Viena sobre relações diplomáticas, de 1961.

A Conferência realizou-se em Viena em atenção a um convite formulado pelo governo austríaco que, com semelhante gesto, estabeleceu um elo entre a mesma e o Congresso de Viena de 1814. O grande evento em Viena, quase um século e meio antes, não apenas representou o fim das guerras napoleônicas, como inaugurou o importante Regulamento sobre a classificação dos diplomatas, representando a primeira codificação sobre a diplomacia. O Regulamento teve o mérito de acabar com as eternas disputas sobre a procedência dos chefes de missão, umas das principais preocupações da diplomacia e frequente motivo de sérias desavenças entre as cortes. As regras adotadas pelo Regulamento de Viena sobre a precedência chegaram aos nossos dias e se acham reproduzidas, mutatis mutandi, nos artigos $14 \mathrm{e}$ 16 da Convenção de Viena de $1961 .^{19}$

18 Nascimento e Silva, G. E. et al., op. cit., pp. 96 e 97.

19 Nascimento e Silva, G. E., Convenção sobre Relações Diplomáticas: a codificação do direito internacional (Viena 1961), Rio de Janeiro, Forense Universitária, 1989, p. 533. 
A incumbência mais importante da Conferência de 1961 foi a de determinar as prerrogativas e imunidades diplomáticas. O consenso prevaleceu sobre as regras básicas conhecidas pelo direito costumeiro e as divergências surgiram na determinação dos beneficiários. A Convenção de 1961 acabou por consolidar a tendência no sentido do deslocamento da principal responsabilidade diplomática da figura do chefe da missão para a embaixada ou legação, entendida em seu conjunto. ${ }^{20}$

O reconhecimento da condição dos agentes diplomáticos, ato já praticado pelos povos desde tempos remotos, veio ao encontro dos propósitos e dos princípios da Carta das Nações Unidas relativos à igualdade soberana dos Estados, à manutenção da paz e da segurança internacional, bem como ao desenvolvimento das relações de amizade entre as Nações. O desenvolvimento das relações amistosas entre as Nações e diferentes povos, independentemente da diversidade dos seus regimes constitucionais e sociais — que já encontrava guarida nos costumes- atingiu seu alto grau de consolidação com a Convenção de Viena de 1961 .

Composta pelo preâmbulo e seus cinquenta e três artigos, a Convenção de Viena sobre Relações Diplomáticas de 1961 definiu os membros componentes da missão, as funções das missões diplomáticas, entre as quais a proteção diplomática de nacionais, bem como uma série de prerrogativas e imunidades. Entre essas últimas, vale destacar a inviolabilidade dos locais da Missão; a obrigação do estado acreditado de adotar todas as medidas apropriadas para proteger os locais da Missão contra qualquer intrusão ou dano e evitar perturbações à tranquilidade da missão ou ofensas à sua dignidade; a inviolabilidade dos arquivos e documentos da Missão, em qualquer momento e onde quer que se encontrem; a inviolabilidade da pessoa do agente diplomático, que não poderá ser objeto de nenhuma forma de detenção ou prisão; igualmente, que o agente diplomático goza de imunidade de jurisdição penal do estado acreditado. ${ }^{21}$

A Convenção de Viena sobre Relações Diplomáticas de 1961 foi decisiva na formulação da Convenção de Viena sobre Relações Consulares, de 1963. Posteriormente, o trabalho de codificação internacional do Direito Diplo-

20 Accioly, H. et al., Manual de direito internacional público, 17a. ed., São Paulo, Saraiva, 2009, p. 198.

21 Obra de autoria coletiva, Direito Internacional, Legislação de, São Paulo, Saraiva, 2009, pp. 133-141. 
Esta revista forma parte del acervo de la Biblioteca Jurídica Virtual del Instituto de Investigaciones Jurídicas de la UNAM

mático foi complementado por mais duas Convenções: a Convenção sobre as missões especiais, adotada pela Assembleia das Nações Unidas em 1969 e a Convenção sobre a representação de Estados em suas relações com organizações internacionais de caráter universal, realizada em Viena, em 1975.

\section{EMER DE VATTEL E A PROTEÇÃO DIPLOMÁTICA DOS NACIONAIS}

A diplomacia exerceu inegável importância no fortalecimento de mecanismos pacíficos de solução de controvérsias. Ao mesmo tempo, desempenhou sua clássica função no sentido de promover os interesses de um determinado Estado, mormente no que diz respeito à busca de negociações econômicas, obtenção de informações, promoção de interesses culturais, além da proteção dos nacionais em outro Estado. ${ }^{22}$

O advento do Estado moderno e a fundação do direito público exigiram a construção de uma organização especificamente dedicada às relações entre Estados. Da mesma forma, com a multiplicação dos Estados soberanos multiplicaram-se os textos alusivos à função dos embaixadores e das embaixadas. Nesse contexto, os juristas ${ }^{23}$ passaram a publicar estudos de modo a sistematizar os problemas relacionados ao tema, como a função dos embaixadores, seus direitos e deveres. ${ }^{24}$

Dentre inúmeras contribuições cumpre destacar a obra de Emer de Vattel, $O$ Direito das Gentes, de 1758, especificamente no que diz respeito à proteção diplomática dos nacionais. A obra do filósofo suíço indubitavelmente encontra-se entre uma das mais importantes obras do século XVIII. Estudioso da filosofia e das humanidades ${ }^{25}$ Vattel especializou-se nas obras

22 Nascimento e Silva, G. E. et al., op. cit., p. 56.

23 Cumpre mencionar, entre outros, a contribuição de Albericus Gentilis, de legationibus libre tres, de 1585 ; de Grócio, Do direito da guerra e da paz; de Wicquefort, Memoires touchant les ambassadeurs et les ministres publics, 1690 e de Leibniz, Codex Iuris Gentium Diplomaticus, 1693.

24 Homem, António Pedro Barbas, História das Relações Internacionais. $O$ direito as concepções políticas na Idade Moderna, Coimbra, Almedina, 2003, p. 125.

25 Koshenniemi, Martii, "International Community from Dante to Vattel”, in Chetail, Vicent e Haggenmacher, Peter (ed.), Vattel' international law in a XXI Century Perspective. Le Droit International deVattel vu du XXI siècle. Geneva Publications, Martinus Nijhoff Publishers, 2011, pp. $49-75$. 
Esta revista forma parte del acervo de la Biblioteca Jurídica Virtual del Instituto de Investigaciones Jurídicas de la UNAM

de Wolff e de Leibniz, reportando-se também a juristas que o precederam, como Grócio, Hobbes, Barbeyrac e Pufendorf. Apesar da forte influência de Wolff, o filósofo suíço não concordava com a criação de uma República universal ou civitas maxima. Vattel foi grande defensor da preservação do Estado. Assim, a preservação da soberania estatal constituía elemento fundamental para a sobrevivência da nação. ${ }^{26}$

Como aduz Vollenhoven (1919, pp. 23-58), a grande contribuição de Vattel diz respeito à ênfase conferida ao princípio da igualdade entre os Estados. ${ }^{27}$ Como expôs Vattel, ${ }^{28}$ “.... a natureza tem estabelecido uma igualdade perfeita de direito entre Nações independentes. Em consequência, nenhuma delas pode, naturalmente, pretender ter prerrogativas superiores às demais".

Para Vattel, o Estado ou a Nação pode ser compreendido como um organismo político ou uma sociedade de homens unidos em conjunto para fim de buscar vantagem e segurança próprias. ${ }^{29} \mathrm{Tal}$ sociedade deve se constituir enquanto uma autoridade pública, por meio da soberania. Quanto à nação considerada em suas relações com outras nações, Vattel assinala o cultivo de relações mútuas, bem como a devida prestação dos ofícios de humanidade. ${ }^{30}$

As nações devem necessariamente tratar e comunicar-se umas com as outras, para o bem de seus negócios, para evitar que se prejudiquem reciprocamente e para ajustar e terminar as suas controvérsias. Segundo Vattel

26 Jouannet, Emmanuelle, Emer deVattel et l'emergence doctrinale du droit internacional public, Paris, Pedone, 1998.

27 Vollenhoven, Cornelius Van, The three stages in the evolution of the law of nations, The Hague, Martinus Nijhoff, 1919, pp. 23-58.

28 Vattel, Emer de, O Direito das Gentes, prefácio e tradução de Vicente Marotta Rangel, Universidade de Brasília, Instituto de Pesquisa de Relações Internacionais, 2004, p. 214.

29 Vattel, op. cit., 2004, p. 15.

30 “Os ofícios de humanidade são esses socorros, esses deveres, a que os homens estão obrigados reciprocamente, na qualidade de homens, ou seja, na qualidade de serem feitos para viver em sociedade, os quais têm necessidade de ajuda mútua, para a própria preservação e felicidade e para viverem de maneira adequada à sua natureza. Ora, desde que as Nações não estão menos submetidas que os particulares às leis naturais §5), os deveres que um homem tem para com outros homens, uma Nação os tem de maneira própria para com outras Nações. Tal é o fundamento desses deveres comuns, desses ofícios de humanidade, aos quais as Nações estão mutuamente obrigadas umas para com outras. Em geral, eles consistem em fazer tudo o que está em nosso poder para o bem-estar e felicidade alheio, à medida que esse dever possa conciliar-se com os deveres acerca de nós mesmos”. Vattel, op. cit., 2004, p. 193. 
Esta revista forma parte del acervo de la Biblioteca Jurídica Virtual del Instituto de Investigaciones Jurídicas de la UNAM

(2014, p.624), nações e soberanos não têm outros meios de comunicar e tratar uns com os outros senão por intermédio de procuradores ou mandatários, de delegados investidos de ordens e poderes, ou seja, de ministros públicos. Todo Estado soberano tem, pois, o direito de enviar e receber ministros públicos, ${ }^{31}$ "pois eles são os instrumentos necessários dos negócios que os soberanos têm uns com os outros, e da correspondência que eles têm o direito de manter". ${ }^{32}$

Embora considere a necessidade de comerciar como imperfeita, o filósofo entende que as nações devem atuar de modo a favorecer o comércio. Para tanto, expõe a relevância dos tratados comerciais e considera a atividade dos cônsules como essencial ao comércio, bem como a merecida proteção especial conferida ao cônsul no país acreditado.

O cônsul, para Vattel, constitui simples comissário dos príncipes designados para tratar dos negócios privados destes. ${ }^{33} \mathrm{O}$ ministro público, denominação conferida aos que estão investidos da qualidade geral de mandatários de um soberano, sem nenhuma atribuição particular de categoria, possui maior proteção do direito das gentes, mormente no que diz respeito às imunidades, embora os cônsules gozem de proteção especial. Em ambos os

31 "Sendo esses os direitos das Nações, o soberano que tenta impedir outro soberano de enviar e receber ministros públicos faz a ele uma injúria e viola o direito das gentes pois, ao fazer isso, ele ataca a Nação em um dos seus mais preciosos direitos, e lhe contesta o que a própria natureza confere a toda sociedade independente. Ele rompe os elos que unem os povos, e assim ofende a todos". Vattel, op. cit., 2014, p. 628.

32 Entre as categorias de ministros públicos, Vattel expõe a figura do Embaixador, este "fica acima de todos os outros ministros que não são investidos com o mesmo caráter e têm precedência sobre eles"; a categoria dos encarregados de negócios "Eles são ministros de segunda categoria, a quem o respectivo soberano desejou conferir um nível de dignidade e de consideração, o qual, sem se comparar com o de embaixador, o segue imediatamente e não é precedido por nenhum outro" e os Cônsules, que segundo Vattel "Eles não são ministros públicos, e consequentemente não estão sob a proteção do direito das gentes. Mas dá-se-lhes uma proteção mais especial que a outros estrangeiros ou cidadãos e também dedica-se-lhes certas deferências em consideração ao príncipe a que eles servem". Vattel, op. cit., pp. 633-635.

33 "Frequentemente, na verdade, eles são cidadãos do país em que residem. Eles não são ministros públicos, e consequentemente não estão sob a proteção do direito das gentes. Mas dá-se-lhes uma proteção mais especial que a outros estrangeiros ou cidadãos e também dedica-se-lhes certas deferências em consideração ao príncipe a que eles servem. Se o príncipe envia um agente com carta credencial e para negócios públicos, o agente é assim constituído ministro público, qualquer que seja o seu título. Diga-se o mesmo quanto a deputados, comissários e outros incumbidos de negócios públicos”. Vattel, op. cit., 2014, p. 635. 
casos, os representantes do Estado acreditante teriam como função precípua a representação e a negociação perante o Estado acreditado.

Nesse sentido, os objetivos internos relativos à busca de vantagem e segurança podem ser compreendidos como equivalentes àqueles buscados na relação de uma nação em relação às demais nações, as quais encontram na figura do ministro público e dos cônsules a máxima representação dos seus interesses alhures. Apesar da prevalência dos interesses do Estado e das relações comerciais, Vattel lobrigou a proteção dos nacionais entre as funções do Estado:

Quem maltrata um cidadão indiretamente injuria o Estado, que deve proteger esse cidadão. O soberano deste cidadão deve vingar-lhe a injúria recebida e, se possível, obrigar o agressor a uma reparação integral, ou puni-lo, uma vez que, de outra maneira, o cidadão não obteria a finalidade básica da sociedade civil, que é a segurança. ${ }^{34}$

Além da hipótese de proteção de nacionais em casos de maus-tratos e ausência de segurança, Vattel coloca ainda a denegação de justiça entre as possibilidades de proteção. Como salienta, o império unido ao domínio dá à nação jurisdição sobre o território que lhe pertence. É à nação, ou a seu soberano, que compete tomar conhecimento dos crimes neles cometidos assim como das controvérsias surgidas no país e fazer justiça nos territórios sujeitos ao seu comando, cabendo às demais nações respeitar esse direito.

E como a administração da justiça necessariamente requer que toda sentença definitiva, pronunciada regularmente, seja considerada como justa e executada como tal, desde que uma causa na qual estrangeiros estão envolvidos foi julgada formalmente, o soberano desses litigantes não mais pode ouvir-lhes as pretensões. ${ }^{35}$

Questionar a justiça de uma sentença definitiva, significa atacar a jurisdição daquele que a proferiu. Segundo Vattel, “o príncipe não deve interferir em causas de seus súditos em país estrangeiro nem, pois, conceder-lhes a sua proteção, exceto em casos de denegação de justiça, ou de injustiça evidente e palpável, ou de manifesta violação das regras". ${ }^{36}$

34 Vattel, op. cit., p. 231.

35 Ibidem, p. 237.

36 Idem. 
Tais considerações somadas ao capítulo dedicado à situação do estrangeiro nos faz concluir que, segundo Vattel, as relações que os estrangeiros mantêm com a sociedade em que se encontram devem seguir os deveres de humanidade, o direito, o interesse e a segurança do Estado que os recebe, bem como os direitos do Estado a que pertencem. ${ }^{37}$ Os estrangeiros estão submetidos às leis do Estado no qual se encontram e "o soberano ao recebê-los, compromete-se a protegê-los como se fossem seus próprios súditos, a fazê-los usufruir, na medida do possível, de perfeita segurança”. ${ }^{38}$

Com efeito, à luz das considerações tecidas por Vattel, nas hipóteses de denegação de justiça, insegurança ou maus-tratos deverá o Estado atuar de modo a proteger seus nacionais que se encontrem em outro Estado. Em tais casos, como a ofensa ao nacional acarreta na injúria indireta do Estado a qual pertence, a busca pela reparação ou punição encontrará legitimidade no direito internacional. Nesse sentido:

O direito internacional reconhece aos Estados a prerrogativa de exercer a proteção diplomática de seus nacionais, entendida como direito do estado, em relação aos seus pares, e não do particular destinatário desta... Assim, o particular, que se veja na contingência de necessitar de tal auxílio, seria antes o objeto da proteção diplomática do que o sujeito desta. ${ }^{39}$

A proteção diplomática, portanto, como uma função governamental para alcançar a segurança e a justiça resulta da própria natureza do Estado. Nesse diapasão, a garantia do bem-estar dos indivíduos constitui função primária do Estado $^{40}$, realizado internamente, mediante direito público interno e externamente, através de instrumentos do direito internacional e da diplomacia. $^{41}$

37 Ibidem, p. 245.

38 Ibidem, p. 247.

39 Casella, op. cit., 2008, pp. 119-123.

40 "Em princípio, a justiça de cada Estado deve limitar-se a punir os crimes cometidos no respectivo território. Mas devem excetuar-se dessa regra os celerados que, pela natureza e frequência habitual dos crimes que praticam, violam toda a segurança pública e se declaram inimigos do gênero humano”. Vattel, op. cit., 2014, p. 156.

41 Borchard, Edwin M., The diplomatic protection of citizen abroad or the law of international claims, New York, The banks law publishing, 1925. 
Esta revista forma parte del acervo de la Biblioteca Jurídica Virtual del Instituto de Investigaciones Jurídicas de la UNAM

\section{A PROTEÇÃO DOS INTERESSES DO ESTADO E DE SEUS NACIONAIS: O INDIVÍDUO COMO OBJETO OU SUJEITO DE DIREITO INTERNACIONAL?}

O artigo $3^{\circ}$ da Convenção de Viena sobre Relações Diplomáticas de 1961 estabelece, entre as funções da missão diplomática: ${ }^{42}$

$1^{\circ}$ As funções de uma Missão Diplomática consistem, entre outras, em:

b) proteger no Estado acreditado os interesses do Estado acreditante e de seus nacionais, dentro dos limites permitidos pelo Direito Internacional.

Qual seria a natureza jurídica do instituto atinente à proteção dos nacionais do Estado acreditante no Estado acreditado, quais seus limites e a possibilidade de extensão às pessoas jurídicas?

De acordo com Nascimento e Silva, Casella e Bittencourt a proteção diplomática dos nacionais, exercida cumulativamente pelas missões diplomáticas e repartições consulares, possuem dois aspectos: a proteção propriamente dita em caso de dano causado ou não pelas autoridades locais; e a simples assistência geral. Para os autores e como considera boa parte da doutrina, "a proteção diplomática é um direito e um dever: direito a ser exercido com relação a um Estado estrangeiro; dever, pelo menos moral, de proteger o cidadão que tenha sofrido um dano". ${ }^{43}$

No que concerne aos limites da proteção diplomática, vimos que na obra de Vattel apenas nos casos de denegação de justiça ou na hipótese de maus-tratos deverá o Estado atuar de modo a proteger seus nacionais que se encontrem em outro Estado. Em tais casos, como a ofensa ao cidadão acarreta na injúria indireta do Estado a qual pertence, a busca pela reparação ou punição encontrará legitimidade no Direito Internacional.

A denegação da justiça, segundo Vattel, refere-se à hipótese de uma completa ausência do devido processo legal. Tendo o estrangeiro obtido uma sentença definitiva justa, pronunciada regularmente, não poderia o Estado, a qual o nacional pertence, levantar questionamentos, uma vez que tal ato significaria "atacar a jurisdição daquele que a proferiu". ${ }^{44}$

42 Obra de autoria coletiva, Direito Internacional, Legislação de, São Paulo, Saraiva, 2009, pp. 133-141.

43 Nascimento e Silva, G. E. et al., op. cit., p.157.

44 Vattel, op. cit., p. 237. 
Esta revista forma parte del acervo de la Biblioteca Jurídica Virtual del Instituto de Investigaciones Jurídicas de la UNAM

A possibilidade de proteção em caso de denegação de justiça levantada por Emer de Vattel no século XVIII encontra na doutrina atual semelhante fórmula, recentemente debatida entre teóricos franceses. A théorie des mains propres $^{45}$ considera que se um nacional é culpado de um delito em um Estado estrangeiro, sendo privado por esse Estado da sua liberdade, ou propriedade, de acordo com as salvaguardas previstas em lei, é improvável que seu estado nacional intervenha para protegê-lo. Na verdade, seria um equívoco por parte do estado da nacionalidade intervir, isso porque nenhum ilícito internacional costuma ocorrer na maioria dos casos. Destarte, a teoria das "mãos limpas" serve justamente para excluir a proteção diplomática em tais hipóteses. Situação distinta é aquela na qual o estrangeiro, acusado de cometer infração, encontra-se sujeito às formas de torturas ou julgamentos considerados injustos. Neste caso, o Estado poderia exercer proteção diplomática em relação ao seu nacional em decorrência de um ato internacionalmente ilícito. ${ }^{46}$ Cumpre salientar ainda que: ${ }^{47}$

La théorie des mains propres ne peut s'appliquer à la personne lésée pour violation du droit international; premièrement, parce que la réclamation acquiert alors une dimension internationale, mettant en jeu des relations d'État à État, et, deuxièmement, parce que l'individu ne jouit pas de la personnalité juridique internationale et qu'il ne peut donc (en dehors du champ du droit pénal international) être tenu pour responsable de la violation du droit international. Bref, par le truchement de la fiction selon laquelle un préjudice causé à un national est un préjudice causé à l'État lui-même, la réclamation présentée au nom d'un national victime d'un fait

45 "Selon la théorie des mains propres, aucune action ne découle d'une infraction délibérée: ex dolo malo non oritur actio. La même notion s'exprime aussi par la maxime nullus commodum capere potest de sua injuria propria. Dans le contexte de la protection diplomatique, la doctrine est invoquée pour empêcher un État d'exercer sa protection diplomatique au bénéfice d'un national si celui-ci a subi un préjudice en raison de son propre comportement illicite". Dugard, John, "Protection Diplomatique [Point 2 de l'ordre du jour]. Sixième rapport sur la protection diplomatique", Annuaire de la Comission du Droit International, vol II, première partie, Documents de la cinquant-septième session des Nations Unies, Genève, 2013, pp. 2-6.

46 CIJ, Caso Avena and Other Mexican Nationals, Judgment, pp. 1-65, 2004. Os nacionais mexicanos cometeram crimes graves nos Estados Unidos, que justificaram a acusação e condenação. Os Estados Unidos, contudo, violaram o direito internacional uma vez que não conferiram aos acusados o benefício da representação consular.

47 Dugard, op. cit., pp. 2-6. 
internationalement illicite devient une réclamation internationale, et la théorie des mains propres peut être invoquée contre l'État responsable uniquement à raison de son comportement, et elle ne peut l'être contre l'individu lésé pour une faute qui aurait été antérieure au fait internationalement illicite. ${ }^{48}$

O reconhecimento da proteção diplomática como um direito eminentemente estatal, um direito próprio do Estado, encontra-se entre as teorias clássicas e mais tradicionais do direito internacional. ${ }^{49}$ Como observamos em Vattel, a concepção segundo a qual uma ofensa ao indivíduo constitui uma ofensa ao Estado de sua nacionalidade coloca os interesses do Estado soberano em detrimento dos indivíduos. Nessa seara, o direito internacional tomava o ser humano na condição de nacional de determinado Estado e, em caso de conflito, seus interesses somente seriam salvaguardados se o Estado, do qual era nacional, decidisse exercer a proteção diplomática. Assim, configurado o direito internacional clássico, como ordenamento regulador das relações entre Estados, a falta de personalidade do indivíduo encontrava a sua contrapartida na responsabilidade do Estado, quando a este fosse imputável dano causado a estrangeiros, em razão da ofensa indireta. ${ }^{50}$

Durante o século XX, a situação da proteção dos seres humanos, enquanto tais, tem desenvolvimento notável quando se passa à questão da proteção dos indivíduos, no plano internacional, não como trabalhador ou como minoria, mas na condição intrínseca de ser humano, no plano internacional. ${ }^{51}$ No mesmo período crescem, no âmbito doutrinário, os questionamentos acerca da nacionalidade como elemento fundamental para a proteção conferida pelo Estado perante o qual a nacionalidade se vincula.

$\mathrm{O}$ vínculo jurídico da nacionalidade tem sua base em um fato social de ligação, uma solidariedade efetiva de existência, de interesses, de sentimentos, aliado à reciprocidade de direitos e deveres e traz a ambiguidade da situação jurídica das pessoas no Direito Internacional. De um lado, temos o Estado, como coletividade política que domina a composição de sua população e a extensão de sua competência, do outro, o reconhecimento a cada

48 Ibidem, pp. 4-5.

49 Anzilotti, Dionisio, La responsabilité internationale des Etats à raison des dommages soufferts par des étrangers, R.G.D.P.I, 1906, pp. 5-30.

50 Casella, op. cit., pp. 123 y 124.

51 Casella, op. cit., p. 125. 
Esta revista forma parte del acervo de la Biblioteca Jurídica Virtual del Instituto de Investigaciones Jurídicas de la UNAM

indivíduo de certa liberdade de escolha para evitar que cometam violações a seus direitos humanos. ${ }^{52}$

Cabe ao Estado, no âmbito de sua soberania e à luz do princípio da competência exclusiva, determinar quais são os seus nacionais, as condições de sua aquisição e perda. Sob tal prisma, a nacionalidade — uma vez considerada competência exclusiva do Estado, bem como justificativa para o uso da proteção diplomática - apresenta um caráter eminentemente estatal.

Em 1923, a Corte Permanente de Justiça Internacional confirmou a supremacia do Estado no que concerne à atribuição da nacionalidade, colocando como limite as obrigações contraídas com outros Estados:

C'est ainsi que, dans l'état actuel du droit international, les questions de nationalité sont, en principe, de l'avis de la Cour; comprises dans ce domaine réservé. Aux fins du présent avis, il suffit de remarquer qu'il se peut très bien que, dans une matière qui, comme celle de la nationalité, n'est pas, en principe, réglée par le droit international, la liberté de l'Etat de disposer à son gré soit néanmoins restreinte par des engagements qu'il aurait envers d'autres Etats. ${ }^{53}$

A decisão da CPJI no caso Mavrommatis, de 1924, reforçou a tese segundo a qual o Estado, ao decidir prendre fait et cause por um de seus nacionais, perante tribunal internacional, não atua como representante ou defensor do protegido, mas defende o seu próprio direito de ver respeitado, na pessoa de seus nacionais, o direito internacional, no território de outros Estados. ${ }^{54}$

É princípio elementar do direito internacional, aquele que autoriza o estado a proteger seus nacionais, lesados por atos contrários ao direito internacional, cometidos por um outro estado, do qual o particular não pode obter satisfação, vias

52 Dinh, Nguyen Quoc et al., Direito Internacional Público, 4a. ed., Paris, Fundação Calouste Gulbenkian, 1992, p. 448.

53 Opinião Consultiva C.P.J.I., no. 4, 1923, p. 24. Différend entre la France et la GrandeBretagne au sujet des décrets de nationalité, promulgués à Tunis et au Maroc (zone française) le 8 novembre 1921, et de leur application aux ressortissants britanniques, le Gouvernement français ayant refusé de soumettre à l'arbitrage la question juridique.

54 CPJI, Recueil 1924, p. 12. Le différend soumis à la Cour par la requête du Gouvernement grec porte sur le point de savoir si c'est à tort que le Gouvernement de Palestine et, à sa suite, le Gouvernement britannique ont refusé depuis 1921 de reconnaître dans toute leur étendue les droits résultant en faveur de M. Mavrommatis des contrats et accords qu'il avait passés avec les autorités ottomanes au sujet de certains travaux. 
Esta revista forma parte del acervo de la Biblioteca Jurídica Virtual del Instituto de Investigaciones Jurídicas de la UNAM

ordinárias. Assumindo o patrocínio da causa por um dos seus, colocando em ação, em favor deste, a ação diplomática ou a ação judiciária, esse estado faz, em sentido estrito, valor o seu próprio direito, o direito que tem de fazer respeitar o direito internacional, na pessoa de seus nacionais... No julgamento do caso da ferrovia Panevezys-Saldutikis, em 1939, a CPJI enfatizou que o direito de proteção diplomática somente pode ser exercido pelo estado, em reação a seus nacionais. ${ }^{55}$

O princípio da competência exclusiva do Estado foi reafirmado pela Corte Internacional de Justiça no julgamento do caso Nottebohm, em 1955, em que a decisão, majoritária, entendeu que deveria se revestir a nacionalidade de cárater de efetividade, o que faltaria no caso da naturalização pelo Liechtenstein. ${ }^{56}$

A complexidade a respeito do tema ganhou forças com o julgamento do caso Barcelona Traction, ${ }^{57}$ em 1970, o qual trouxe à baila a proteção de nacionais envolvendo pessoas jurídicas e interesses econômicos. Segundo a Corte, uma distinção essencial deve ser estabelecida entre as obrigações de um Estado perante a comunidade internacional no seu conjunto e aquelas que nascem tendo em vista um outro Estado no âmbito da proteção diplomática. Pela sua própria natureza, as primeiras dizem respeito a todos os Estados. Dado a importância dos direitos envolvidos, todos os Estados podem ser considerados como tendo um interesse jurídico para que tais direitos sejam protegidos. As obrigações perante as quais a proteção diplo-

55 Casella, op. cit., p. 121.

56 Idem. A ausência de efetividade não por ser derivada, mas pela descontinuidade no tempo entre o dano sofrido por ele e a aquisição da nacionalidade, razão pela qual não pôde ser considerada substancial. Exigência de vínculos sólidos.

57 Barcelona Traction, Light and Power Company, sociedade constituída em 1911, em Toronto, onde se encontra a sua sede. Em vias de criar e desenvolver na Catalunha uma rede de produção e distribuição de energia elétrica, a empresa acabou por fundar várias sociedades auxiliares, algumas com sede no Canadá, outras na Espanha. Essas sociedades auxiliares adquiriram a maior parte dos bens da Catalunha no setor de eletricidade. Segundo o governo belga, grande parte das ações da Barcelona Traction foram adquiridas por nacionais belgas depois da primeira guerra mundial. O governo espanhol, por sua vez, argumentou que a nacionalidade belga dos acionistas não foi estabelecida. A Barcelona Traction tinha uma série de obrigações de prestação de serviços na Espanha, garantidas graças às atividades das sociedades auxiliares. Em 1936, os serviços foram interrompidos em razão da guerra civil. Com o término desta, o controle das sociedades auxiliares passou ao governo espanhol, que se recusou a autorizar a transferência de fundos necessários para retomar as obrigações de serviço. CIJ, l'affaire de Barcelona Traction light and Power Company, Recueil, 1970. 
Esta revista forma parte del acervo de la Biblioteca Jurídica Virtual del Instituto de Investigaciones Jurídicas de la UNAM

mática tem por objeto assegurar o cumprimento não fazem parte da mesma categoria. Para a Corte, a proteção diplomática compreende um setor muito delicado das relações internacionais uma vez que o interesse de um Estado estrangeiro para proteger seus cidadãos colide com os direitos da soberania territorial". ${ }^{58}$

Segundo a Corte Internacional de Justiça, estreitamente ligada desde sua origem ao comércio internacional, a proteção diplomática passou pelo desenvolvimeno das relações econômicas internacionais. Essas mudanças resultaram em instituições de direito interno que transbordaram os limites e passaram a exercer uma influência considerável sobre as relações internacionais. ${ }^{59}$ Em matéria de proteção diplomática, a Corte reitera que a prova de um prejuízo não constitui causa suficiente de modo a justificar uma reclamação diplomática. Tratando-se de um ato ilícito contra uma sociedade de capital estrangeiro, a regra geral do direito internacional não autoriza que o Estado nacional desta sociedade exerça sua proteção diplomática para obter reparação. ${ }^{60}$

Seidl-Hohenveldern apud Casella,${ }^{61}$ destaca a necessidade de ajustar o conceito tradicional da proteção diplomática à realidade do mundo pós-moderno, porquanto a maior parte dos investimentos estrangeiros, atualmente, se faz por meio de pessoas jurídicas. Nesse sentido, destacou a relevante mudança de concepção em matéria de proteção de interesses econômicos no âmbito da proteção diplomática a partir da decisão do caso Barcelona Traction.

58 CIJ, Recueil, 1970, pp. 33 e 34.

59 «Dans ce domaine, le droit international est appelé à reconnaître des institutions de droit interne qui jouent un rôle important et sont très répandues sur le plan international. Il n'en résulte pas nécessairement une analogie entre ses propres institutions et celles du droit interne et cela ne revient pas à faire dépendre les règles du droit international de catégories de droit interne. Cela veut simplement dire que le droit international a dû reconnaître dans la société anonyme une institution créée par les Etats en un domaine qui relève essentiellement de leur compétence nationale. Cette reconnaissance nécessite que le droit inter national se réfère aux règles pertinentes du droit interne, chaque fois que se posent des questions juridiques relatives aux droits des Etats qui concernent le traitement des sociétés et des actionnaires et à propos desquels le droit international n'a pas fixé ses propres règles. C'est pourquoi, vu la pertinence en l'espèce des droits de la société anonyme et des droits des actionnaires dans l'ordre interne, la Cour doit examiner leur nature et leur interaction». CIJ, Recueil, 1970, pp. 34 e 35.

60 CIJ, Recueil, 1970, pp. 37 e 38.

61 Casella, op. cit., p. 161. 
Esta revista forma parte del acervo de la Biblioteca Jurídica Virtual del Instituto de Investigaciones Jurídicas de la UNAM

Segundo Ngyuen Quoc Dinh et al. (1992, p. 906), ${ }^{62}$ os questionamentos de acionistas e suas consequentes obrigações de uma sociedade podem obter proteção diplomática na defesa de seus direitos e interesses podem ser facilmente respondidos quando há dois Estados na causa, o Estado da sede social e o Estado nacional dos acionistas, uma vez que o problema pode ser resolvido em referência aos princípios que regem a atribuição da nacionalidade às sociedades. O problema complica quando há três Estados em causa: o Estado responsável, o Estado nacional da sociedade e o Estado nacional da maioria dos acionistas. Trata-se do caso Barcelona Traction, no qual a CIJ recusou admissão da reclamação do Estado dos acionistas — a Bélgicadepois que o Estado da sociedade — C Canadá, renunciou ao exercício de sua proteção diplomática.

No que concerne ao esgotamento dos recursos internos em matéria de proteção diplomática, Dinh (1992, pp. 906-907) salienta que um Estado não pode introduzir uma reclamação antes que o particular, vítima do ato ilícito, tenha utilizado todos os recursos internos previstos e colocados à disposição pela ordem jurídica do Estado perante o qual se busca a reparação.

De acordo com Cançado Trindade, ${ }^{63}$ a regra do esgotamento dos recursos internos tem e teve, no plano do direito internacional geral, um caráter nitidamente preventivo, constituindo-se em conditio sine qua non ao exercício da proteção diplomática. Nesse contexto, tal regra permitiu que as tensões nas relações internacionais fossem minimizadas e assegurou, no contencioso diplomático, uma certa medida de respeito pela soberania dos Estados. Cumpre salientar que Trindade faz diferenciação da regra no contexto da proteção diplomática em caso de responsabilidade do Estado por danos causados a estrangeiros e no caso da proteção dos direitos humanos. No contexto da responsabilidade, o estado reclamado a invoca antes do exercício da proteção diplomática. Já quanto aos direitos humanos, a regra opera em geral como pré-requisito da admissibilidade de reclamações ou petições, independentemente da nacionalidade do reclamante.

62 Dinh et al., op. cit., p. 906.

63 Cançado Trindade, Antônio Augusto, $O$ esgotamento dos recursos internos e a evolução da noção de «vítima» no direito internacional dos Direitos Humanos, trabalho de pesquisa apresentado pelo autor em forma de conferência ministrada no IV Curso Interdisciplinar em Direitos Humanos, no Instituto intermamericano de Direitos Humanos, em São José, Costa Rica, em 22 de agosto de 1986, disponível em: http: / / www.juridicas.unam. mx/publica/librev/rev/iidh/ cont/3/dtr/dtr1.pdf (acesso em 12.06.2015). 
O tema relativo à proteção diplomática envolve, ademais, os meios e as formas de exercício que, segundo Dinh (1992, p. 909), podem abranger soluções ofertadas pelo direito internacional, desde representações e consultas diplomáticas até meios arbitrais e jurisdicionais. Observa ainda que a proteção diplomática não pode constituir um pretexto para o emprego de meios ilícitos pelo direito internacional, como o uso da força.

Por derradeiro, Dinh confere avaliação aos problemas relativos à renúncia da proteção diplomática. Nesse sentido, resta pouca discussão no que concerne à renúncia do Estado, uma vez que este não pode renunciar ao exercício de sua proteção diplomática, seja por um tratado ou por uma declaração unilateral, anterior ou posterior a um litígio. A hipótese delicada diz respeito à renúncia pelo particular consubstanciada num acordo ou contrato com outro Estado, sem o aval do Estado suscetível de exercer sua proteção diplomática. Tal renúncia seria oponível?

Cette situation est née d'une ratique latino-américaine, imaginée par l'homme d'État argentin Calvo (1824-1906) —d'où le nom générique de «clause Calvo»qui consiste à inserer dans un contrat de concession, à la demande de l'autorité concédante, une disposition selon laquelle le concessionnaire étranger s'engage à ne pas demander la protection diplomatique de son État d'origine en cas de litige. L'investisseur étranger accepte de n'útiliser que les vois de recours internes. ${ }^{64}$

Nesse sentido, por força da cláusula, o nacional não poderia invocar o seu Estado de origem, estando este impedido de exercer a sua proteção diplomática. A jurisprudência, como expõe Dinh, vem confirmando a posição formulada pelos Estados Unidos desde 1888, que refuta a possibilidade de um nacional, por um simples contrato, anular a relação jurídica existente entre o seu Estado ou sumpimir a obrigação deste de protegê-lo em caso de uma justiça denegada. Tal reação explica a vontade de os Estados conservarem a competência em matéria de proteção diplomática. Assim, a tese de ilicitide da claúsula Calvo conforta a ficção segundo a qual o Estado exerce um direito que lhe é próprio, não podendo o particular renunciar a algo que não diz respeito à sua competência. ${ }^{65}$

A discussão a respeito da Cláusula Calvo envolve o caso North American Dredging Company ofTexas (U.S.A.) v. United Mexican States, submetido

64 Dinh et al., op. cit., p. 910.

65 Ibidem, pp. 910-911. 
Esta revista forma parte del acervo de la Biblioteca Jurídica Virtual del Instituto de Investigaciones Jurídicas de la UNAM

perante a Comissão Geral criada no âmbito da Convenção celebrada entre os Estados Unidos e México, em 1923. O caso colocado perante a Comissão pelo Governo dos Estados Unidos em nome da North American Dredging Company para a recuperação do montante de US \$233,523,30 por perdas e danos alegadamente sofridos pela Companhia por violação de um contrato no porto mexicano. O contrato foi assinado entre a Companhia e o Governo do México, na Cidade do México, e continha uma Cláusula Calvo , levando-se em conta que o contratante e todas as pessoas fossem considerados como os mexicanos em todos os assuntos, dentro da República do México, sobre a execução do trabalho, bem como o cumprimento do contrato. No momento da realização do contrato, a Companhia concordou em não invocar a proteção diplomática em qualquer assunto relacionado ao contrato. A Comissão chegou a afirmar, à luz da proteçao diplomática, que os Estados possuem o direito de proteger os seus cidadãos quando sujeitos a discriminação ou tratamento indevido no exterior. A Cláusula Calvo não limita este direito, limitando-se a impor aos estrangeiros certas condições à luz da legislação internacional. ${ }^{66}$

No final do seculo XX, a evolução da proteção diplomática culminou no Projeto da Comissão de Direito Internacional das Nações Unidas sobre proteção diplomática, adotada em 2006. De acordo com o art. $1^{\circ}$ do Projeto, a proteção diplomática « consiste na invocação, por um Estado — através de ação diplomática ou outros meios de resolução pacífica-, da responsabilidade de um outro Estado por um dano causado por ato ilícito internacional do segundo Estado a uma pessoa natural ou jurídica que é nacional do primeiro Estado mencionado, com vista à implementação de tal responsabilidade". O art. $3^{\circ}$, estabelece que "O Estado que tem o direito de exercer a proteção diplomática é o Estado da Nacionalidade [da pessoa lesada]. Não obstante, "a proteção diplomática pode ser exercida por um Estado, em relação a uma pessoa, que não é seu nacional, em conformidade com o artigo $8^{\circ}$, relacionado aos apátridas e refugiados. Os artigos 9 ao 13 do projeto conferiram atenção às pessoas jurídicas, relacionados ao Estado de nacionalidade de uma Empresa e à proteção de acionistas. O artigo 10 do projeto levou em conta a nacionalidade contínua de uma Empresa, estabelecendo que: i) Um Estado tem o direito de exercer a proteção diplomática em

66 North American Dredging Company of Texas (U.S.A.) v. United Mexican States, Recueil, disponível em: http://legal.un.org/riaa/cases/vol_IV/26-35.pdf. 
relação a uma empresa que era nacional daquele Estado ou de seu Estado predecessor, continuamente, desde a data do dano até a data da propositura oficial da ação; ii) Um Estado não tem mais o direito de exercer a proteção diplomática em relação a uma empresa que adquire a nacionalidade do Estado contra o qual a ação é movida depois da propositura da ação e iii) Não obstante o Parágrafo 1, um Estado continua a ter o direito de exercer a proteção diplomática em relação à empresa que era sua nacional na data do dano e a qual, como resultado do dano, cessou de existir de acordo com a legislação do Estado no qual se constituiu. Quanto à proteção dos acionistas, o artigo 11 prevê que: um Estado de nacionalidade dos acionistas de uma empresa não terá direito a exercer a proteção diplomática em relação a tais acionistas no caso de dano à empresa, a menos que: a) a empresa tenha cessado de existir, de acordo com a legislação do Estado onde se constituiu, por motivo não relacionado ao dano, ou b) a empresa tivesse, na data do dano, a nacionalidade do Estado supostamente responsável pelo dano, e sua constituição naquele Estado fosse uma exigência deste Estado para que ela pudesse realizar suas atividades naquele lugar. ${ }^{67}$

Os critérios tomados pelos elaboradores do projeto parecem ter levado em consideração a decisão da Corte Internacional de Justiça no caso Barcelona Traction e outros casos igualmente submetidos à apreciação das cortes internacionais, reforçando o papel da jurisprudência como fonte de direito internacional.

\section{CONCLUSÃO}

O indivíduo, como vimos na doutrina tradicional, não possui a legitimidade de invocar dispositivos do direito internacional, justamente em razão da sua qualidade de objeto do direito internacional. Sob tal prisma, o Estado violador fere a honra do estado da vítima, o qual detém legitimidade para, nos limites do direito internacional, exigir a devida reparação. Em tal contexto, a nacionalidade acaba por desempenhar um vínculo necessário para o exer-

67 Draft Articles on Diplomatic Protection, Disponível em: http://legal.un.org/ilc/texts/ instruments/english/commentaries/9_8_2006.pdf. 
cício da proteção, deixando os indivíduos sob completa tutela dos Estados no plano internacional.

Durante muito tempo a doutrina e a jurisprudência reiteraram a condição do Estado como principal sujeito de direito internacional, colocando a proteção diplomática de nacionais como um direito essencialmente estatal.

O fortalecimento da proteção dos direitos humanos e o desenvolvimento da economia internacional na passagem do século XX para o século XXI impulsionaram novos questionamentos em matéria de proteção diplomática. No primeiro caso, a necessidade de ajustamento de um sistema que leve em conta a proteção dos indivíduos, independentemente do vínculo estatal, isto é, uma proteção que coloque o ser humano como sujeito de direito, dispensando a nacionalidade como vinculum iuris para o exercício de tal proteção. No segundo, o imperativo de adaptação de uma realidade que envolve de forma constante o grande fluxo de investimentos estrangeiros, realizado sobretudo por meio de pessoas jurídicas. Como pensar a proteção do indivíduo independentemente de sua nacionalidade? Como adaptar a proteção diplomática à realidade da economia mundial?

Com efeito, verifica-se que em um mundo no qual as mudanças são cada vez mais velozes, o direito internacional não pode se acomodar na manutenção de uma visão tradicional que não responde aos dilemas da atualidade. Nesse contexto, a doutrina e os estudiosos do direito exercem a tarefa, relevante e premente, de acompanhar as mudanças, traçar diagnósticos e apontar para as eventuais soluções de problemas, sobretudo, de ajustar os conceitos tradicionais à realidade do mundo pós-moderno.

\section{BIBLIOGRAFIA}

ACCiOly, Hildebrando, Tratado de direito internacional público, São Paulo, Quartier Latin, 2009.

- et al., Manual de direito internacional público, 17 ed., São Paulo, Saraiva, 2009.

ANZILOTTI, Dionisio, La responsabilité internationale des Etats à raison des dommages soufferts par des étrangers, R.G.D.P.I., 1906.

BibliothèQue Diplomatique Comte D’Angeberg, Le Congrés de Vienne et les traités de 1815, Paris, Amyot éditeur des archives diplomatiques, 1937. 
Esta revista forma parte del acervo de la Biblioteca Jurídica Virtual del Instituto de Investigaciones Jurídicas de la UNAM

BORCHARD, Edwin M., The diplomatic protection of citizen abroad or the law of international claims, New York, The Banks Law Publishing, 1925.

CASElla, Paulo Borba, Direito internacional no tempo antigo, São Paulo, Atlas, 2012.

, Fundamentos do direito internacional pós-moderno, São Paulo, Quartier Latin, 2008.

CAnÇADO TRINDAdE, Antônio Augusto, $O$ esgotamento dos recursos internos e a evolução da noção de «vítima» no direito internacional dos Direitos Humanos, trabalho de pesquisa apresentado pelo autor em forma de conferência ministrada no IV Curso Interdisciplinar em Direitos Humanos, no Instituto interamericano de Direitos Humanos, em São José, Costa Rica, em 22 de agosto de 1986. Disponível em: http: / / www.juridicas.unam.mx/ publica / librev/rev/iidh/cont/3/dtr/dtr1.pdf

(ACESSO em 12.06.2015).

Despagnet, Frantz, Cours de Droit International Public, Paris, Elibron Classics, 2006.

DinH, Nguyen Quoc et al., Droit International Public, 4a. ed., Paris, Fundação Calouste Gulbenkian, 1992.

DuGARD, John, "Protection Diplomatique. Sixième rapport sur la protection diplomatique", Annuaire de la Comission du Droit International, vol II, première partie, Documents de la cinquant-septième session des Nations Unies, Genève, 2013.

Flassan, Gaetan de Raxis, Histoire du Congrés deVienne, Paris, Chez Treuttel et Wurtz Libraire, 1829.

Homem, António Pedro Barbas, História das Relações Internacionais. O direito as concepções políticas na Idade Moderna, Coimbra, Almedina, 2003.

JouAnNET, Emmanuelle, Emer deVattel et l'emergence doctrinale du droit internacional public, Paris, Pedone, 1998.

Koshenniemi, Martii, "International Community from Dante to Vattel", in Chetail, Vicent e Haggenmacher, Peter (ed.), Vattel'international law in a XXI Century Perspective. Le Droit International deVattel vu du XXI siècle. .Geneva Publications, Martinus Nijhoff Publishers, 2011.

Morton, W. Scott, China: história e cultura, Rio de Janeiro, Zahar Editores, 1986.

Nascimento e SiLva, G. E. Convenção sobre Relações Diplomáticas: a codificação do direito internacional (Viena 1961). Rio de Janeiro: Forense Universitária, 1989. 
et al., Direito Internacional Diplomático. Convenção de Viena sobre Relações Diplomáticas na Teoria e na Prática, São Paulo, Saraiva, 2012.

Obra de autoria coletiva, Direito Internacional, Legislação de, São Paulo, Saraiva, 2009.

SPENCE, Jonathan D., Em busca da China moderna: quatro séculos de história, trad. de Tomás R. Bueno e Pedro M. Soares, São Paulo, Companhia das Letras, 1996.

TRuYOL y Serra, História del Derecho Internacional Público, Madrid, Tecnos, 1998.

VATtel, Emer de, $O$ Direito das Gentes, prefácio e tradução de Vicente Marotta Rangel, Universidade de Brasília, Instituto de Pesquisa de Relações Internacionais, 2004.

Vollenhoven, Cornelius Van, The three stages in the evolution of the law of nations, The Hague, Martinus Nijhoff, 1919.

Fontes jurisprudenciais

C.I.J., caso Pessoal diplomático e consular dos Estados Unidos em Teerã, 1979.

C.I.J., caso Avena e outros Nacionais Mexicanos, 2004.

C.I.J., caso Barcelona Traction light and Power Company, 1970.

C.PJ.I, Opinião consultiva, $\mathrm{n}^{\circ} 4,1923$, decretos acerca da nacionalidade na Tunísia e no Marrocos, 1921.

C.P.J.I., Caso M. Mavrommatis, 1924. 